\title{
New Test Results in Cycloid-Forming Trochoidal Milling
}

\author{
István Szalóki, Sándor Csuka, Sándor Sipos \\ Óbuda University, Donát Bánki Faculty of Mechanical Engineering \\ Népszínház u. 8, H-1081 Budapest, Hungary \\ szaloki.istvan@bgk.uni-obuda.hu, csuka.sandor@bgk.uni-obuda.hu, \\ sipos.sandor@bgk.uni-obuda.hu
}

\begin{abstract}
The different types of trochoidal milling are widely used in order to produce grooves and slots. These procedures can be purchased as a built-in option of modern controls or they can be generated by modelling the movements of the tool path. In addition to the advantages, arising during machining (lower load on the milling tool and machine, the possibility to apply increased cutting parameters, raised productivity and tool durability) there is a disadvantage, to be mentioned: it is the forming of laces on the machined surface. In the present paper our trials will be introduced where a modelled cycloid-forming milling method is used to determine the effect of the cutting data, performed on the result parameters (force effects, accuracy, surface microgeometry). The tests were executed systematically, with the help of Experiment Design. Based on the results, gained during the tests, the force, accuracy and microgeometrical limits can be determined, being characteristic to this machining type.
\end{abstract}

Keywords: slot milling; semicircular milling; zigzag milling; trochoid milling; productivity; force effects; microgeometry

\section{Introduction}

The slot (or groove) milling is used in the production of axis symmetric parts to form torque transmitting surfaces. Based on the accuracy of the machining, there are operations of general and increased accuracy. The slots, acting as necessary for the cirlclip of bearings, match the firstly mentioned group, while the slots of fixed and movable locking connections, having a tight tolerance (more precise than tolerance class IT9), belong to the second type [1]. The necessary depth of groove of some components, machined with groove milling, may achieve or even exceed the value of the tool diameter $\left(a_{p}>d\right)$. In this case the machining may be a roughing operation of a groove, used as a part of a large-sized cog-wheel or a surface for fixing blades in a turbine. The so-called one-step general milling is inaccurate due to the fact that the tool contacts the workpiece with a very long edge section, as a 
result of it, an increase in the cutting force and temperature can be noticed. The momentaneous chip thickness causes an unsteady load on the edge; the disadvantageous chip transport often leads to chip re-cutting. Although general milling is usually a productive operation, it is accompanied with unfavourable tool edge durability and increase of the machining costs. The earlier described unfavourable phenomena may lead to even more disadvantageous results in case of hard-to-machine materials.

We use the expression of trochoidal milling if the tool path contains the combination of circle and straight line, or it is cycloid-like; the width of the groove (bw) is made with a milling tool, having a diameter of at least $1.15 \mathrm{x} \mathrm{d}$, the value of the radial step-over is between $0.02 \ldots 0.25 \mathrm{x} \mathrm{d}$ [2]. The trochoidal movement cycle can be considered as a type of cylindrical milling, the realizable accuracy and the surface roughness (waviness and roughness) is subject to the applied strategy. The radial depth of cut $\left(\mathrm{a}_{\mathrm{e}}\right)$ is continuously changing during the machining, the radial step over, indicated during the design process of the tool path, and influences the momentary value of the maximal radial contact $\left(\mathrm{a}_{\mathrm{emax}}\right)$ to a great extent. From the aspect of the process reliability it is essential to have exact information of this value.

According to the literatures [2-4], the trochoidal milling methods have the following benefits:

- it is effective in case of high strength pieces, or even in case of hardened workpieces with small wall thickness,

- the axial depth of cut is relative great (its typical value is in the range of 10 and $20 \mathrm{~mm}$ ), while the radial depth of cut is smaller as usual,

- the productivity can be raised considerably by applying increased cutting speed and feed values,

- the tool life and the surface roughness are generally favourable,

- the programmed milling strategies prevent the machining system from damage,

- the utilization and the productivity of the devices will increase.

Without doubt, an intensive acceleration and deceleration is demanded from the machine tool, while a look-ahead function is required from the control in case of application of this milling type. The rigid connection of the tool clamping system and the possible smallest overhang of milling cutter are also important facts, to be considered.

This research topic was developed with the purpose to determine the dependence of the characteristics, to be examined via instrumental measurements, on the cutting parameters with analysing the precisily modelled cycloid-forming trochoidal milling for the determination of the force effects and the productivity; moreover, the development of the quality of the grooves and of the surface roughness were also analysed. 


\section{Modelling the Cycloid-Forming Trochoidal Milling}

The cycloid-forming milling is a built-in option in several modern CNC controls, but this application is control specific and the activation of the movement cycles means huge costs. Also for this reason it is reasonable to create a uniform program, enabling the possibility to serve most controls. Microsoft Office Excel application was used to program the tool paths. The description was prepared in a parametric way, so the recalculation of the tool path points is automatically made if there is a change in any of the initial data $\left(\mathrm{d}, \mathrm{b}_{\mathrm{w}}, \mathrm{w}\right.$ etc.); after that the $\mathrm{NC}$ program, written in ISO programming language, is created in a form, being easily adjustable to the applied control [3].

The tool movement paths of the cycloid-forming

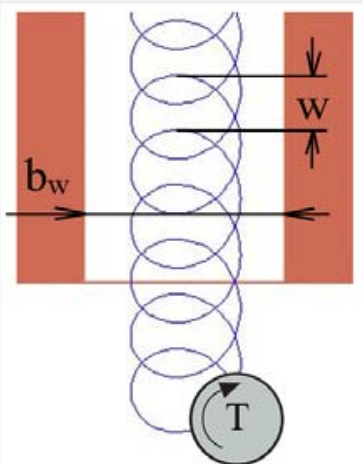

Figure 1

Cycloid-forming milling milling strategy are shown in Figure 1. The tool is controlled on a path, having a looped cycloid form; it is really advantageous from the aspect of the tool load.

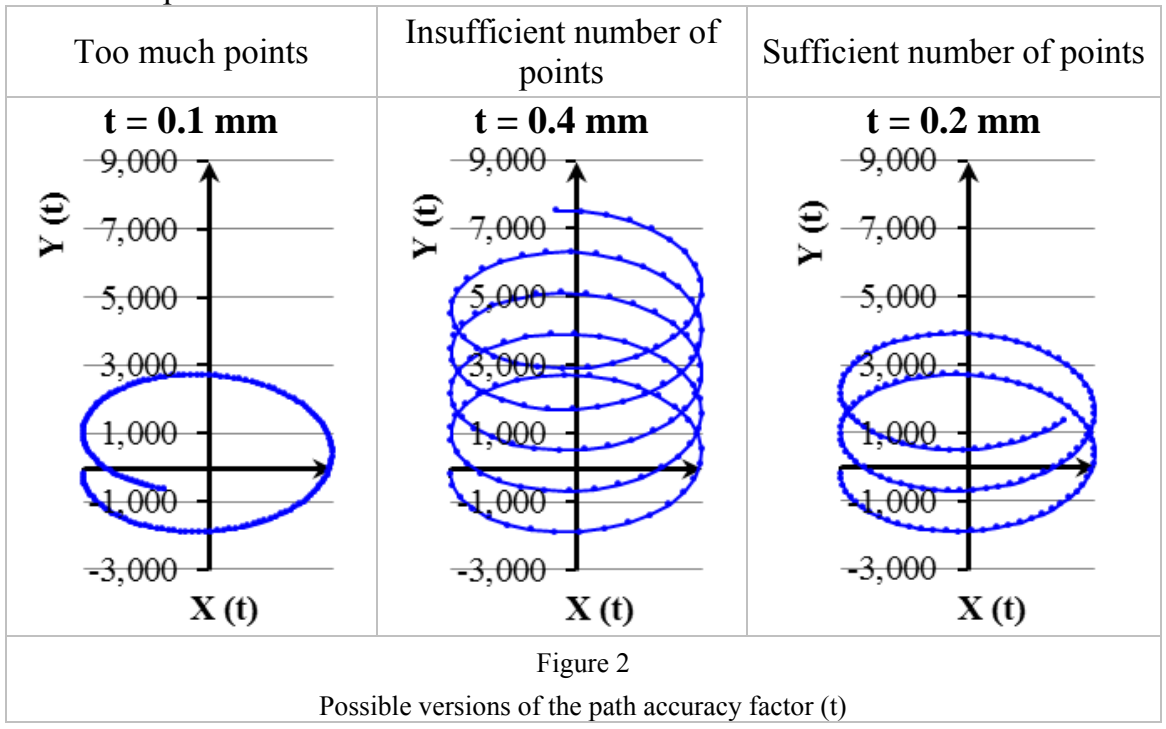

The most important characteristic is the length of the chord $(t)$ to create a cycloid path; it is called as the path accuracy factor. This feature means the length of all lines, forming the generated path, and it determines the accuracy, ,angularity” of the path. Its optimal value is between $t=0.1 \ldots 0.3 \mathrm{~mm}$ (Figure 2). If this value is greater than $0.3 \mathrm{~mm}$, then it may lead to unfavourable wear and to a decreasing 
tool life because of the uneven load. If the chord length value is smaller than 0.1 $\mathrm{mm}$, then the model contains too many generated points and it may lead to problems when reading, storing and processing data. Thus the tool path generation was made with a value of $\mathrm{t}=0.2 \mathrm{~mm}$ in our tests [5].

\section{The Research of the Cycloid-Forming Trochoidal Milling (CTM)}

The most important aim of the tests was to analyse the effect of the cutting parameters and to answer the question how the test conditions affect the features (for example, force effects), developing during the trochoidal milling, and how they may influence the result parameters (accuracy, microgeometry), being in connection with product quality. Considering the fact that the cutting speed value was kept on a constant level, so the number of data, to be set, was reduced to three; in this way the Design of Experiment (DoE) contains the analysis of three variables $\left(a_{p}, a_{e m}, f_{z}\right)$, varying them on three (minimal, medial and maximal) levels. From the possible 27 settings only 6 were applied, in this way material, tool, time and, of course, money could spared without losing important information. With the consistent execution of DoE (shown in Table 1) appropriate mathematical models were established, being able to describe the probable results of cutting operations even in case of not measured settings. This fact was verified by executing two check tests (7E and $8 \mathrm{E}$ ).

The test were executed in the workshop of Donát Bánki Faculty of Mechanical and Safety Engineering of Óbuda University, on a vertical machining center (type: MAZAK Nexus 410A, control: Mazatrol ${ }^{\mathrm{TM}}$ ), which is installed to carry out tool test experiments, equipped with a device for blowing cold, compressed air. The force examinations were simple by using a dynamometer (type: Kistler 9257) and by DynoWare ${ }^{\mathrm{TM}}$ software to evaluate the results. The microgeometrical results were gained by using Mahr-Perthen Perthometer PRK Concept-2D, 3D surface analysing device.

Workpieces with dimensions of $160 \times 50 \times 50$ $\mathrm{mm}$ were used to carry out the tests, they had the following parameters: grade $40 \mathrm{CrMnMo} 7$ (DIN standard W. Nr. 1.2391), pre-tempered to approx. $1000 \mathrm{MPa}$ and its hardness was always verified (HB285 \pm 5$)$.

The monolith cemented carbide HPC shank milling cutter (type: R215.36-12060-AC26L, Figure 3), having a diameter of $ø 12 \mathrm{~mm}$, was provided by SANDVIK Magyarország Kft.

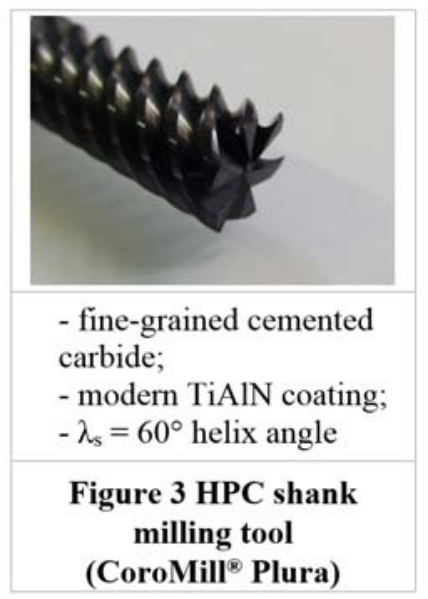


During the tests, the tool was clamped in a cold shrink adapter, with EMUGEFRANKEN clamping system (PGR ,powRgrip ${ }^{\mathbb{B}}$ ). The tool overhang was $40 \mathrm{~mm}$; the run-out of the milling cutter was $0.01 \mathrm{~mm}$.

The applied settings and test conditions are shown in Table 1 . The feed $\left(\mathrm{F}_{\mathrm{f}}, \mathrm{N}\right)$ and axial force $\left(\mathrm{F}_{\mathrm{z}}, \mathrm{N}\right)$ components were measured with the force measuring cell. The tests were completed with the following result parameters: time and productivity analysis, accuracy examination and roughness analysis.

Table 1 Machining conditions

\begin{tabular}{|c|c|c|c|c|c|c|c|}
\hline \multirow{2}{*}{ 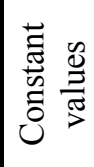 } & \multicolumn{2}{|c|}{$\begin{array}{c}\text { Cutting speed, } \\
\mathbf{v}_{\mathrm{c}}, \mathrm{m} / \mathrm{min}\end{array}$} & $\begin{array}{c}\text { Rpm, } \\
\text { n, } \text { min }^{-1}\end{array}$ & $\mathbf{l}_{\mathrm{w}}, \mathbf{m m}$ & $\mathbf{b}_{\mathrm{w}}, \mathbf{m m}$ & \multicolumn{2}{|c|}{ Cooling } \\
\hline & \multicolumn{2}{|c|}{$\sim 120$} & 3180 & 45 & 16 & \multicolumn{2}{|c|}{ ColdAirGun $^{\mathrm{TM}}$} \\
\hline \multirow{10}{*}{ 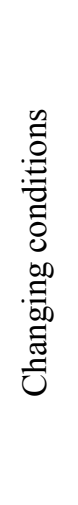 } & \multicolumn{3}{|c|}{ COMMON VALUES } & \multicolumn{2}{|c|}{ 1ST BLOCK } & \multicolumn{2}{|c|}{ 2ND BLOCK } \\
\hline & $\begin{array}{l}\text { O. } \\
\text { Nr. }\end{array}$ & $\mathbf{a}_{\mathrm{p}}, \mathbf{m m}$ & $\mathbf{a}_{\mathrm{em}}, \mathbf{m m}$ & $\mathbf{f}_{\mathrm{z}}, \mathbf{m m}$ & $\begin{array}{c}\mathbf{v}_{\mathrm{f}}, \\
\mathrm{mm} / \mathrm{min}\end{array}$ & $\mathbf{f}_{\mathbf{z}}, \mathbf{m m}$ & $\begin{array}{c}\mathbf{v}_{\mathbf{f}}, \\
\mathrm{mm} / \mathrm{min}\end{array}$ \\
\hline & 1. & 9 & 3.2 & 0.1 & 477 & 0.14 & 668 \\
\hline & 2. & 9 & 3.9 & 0.08 & 382 & 0.12 & 573 \\
\hline & 3. & 12 & 3.2 & 0.12 & 573 & 0.16 & 764 \\
\hline & 4. & 12 & 3.9 & 0.1 & 477 & 0.14 & 668 \\
\hline & 5. & 12 & 4.5 & 0.08 & 382 & 0.12 & 573 \\
\hline & 6. & 16 & 4.5 & 0.12 & 573 & 0.16 & 764 \\
\hline & 7E. & 9 & 4.5 & 0.12 & 573 & 0.16 & 764 \\
\hline & $8 E$. & 16 & 3.9 & 0.1 & 477 & 0.14 & 668 \\
\hline
\end{tabular}

where: $1_{w}-$ groove length; $b_{w}-$ groove width; $a_{p}-$ axial depth of cut, $a_{e m}-$ maximal contact width; $\mathrm{f}_{\mathrm{z}}-$ feed per tooth; $\mathrm{v}_{\mathrm{f}}-$ feed rate

\subsection{The Force Analysis and Modelling of the Cycloid-Forming Trochoidal Milling (CTM)}

Based on the three components, registered by KISTLER force measuring cell and processed by Dynoware software, the minimum/average/maximum values can be determined. Analysing the high resolution (ZOOM) registratums of force sample values (Figure 4), the following conclusions can be drawn:

- According to the axial force $(\mathrm{Fz})$ sample, the tool is continuously trying to lift up the workpiece, it is confirmed by the negative value range as well (it is shown on the upper part of Figure 4). This can be traced back to the very high helix angle of milling cutter. At the moment before the tool tooth leaves the workpiece, the force value becomes positive, it means that the clamping down effect becomes dominant (see „Max”). Considering the fact that the 
greatest part of the forces has a lifting character, therefore the positive values may cause just a small distortion when calculating the average values („Mean”). The values of six settings describe the effect of the cutting parameters, performed on the axial force components with quite certainty when processing the results of the trials, executed based on the Design of Experiment.

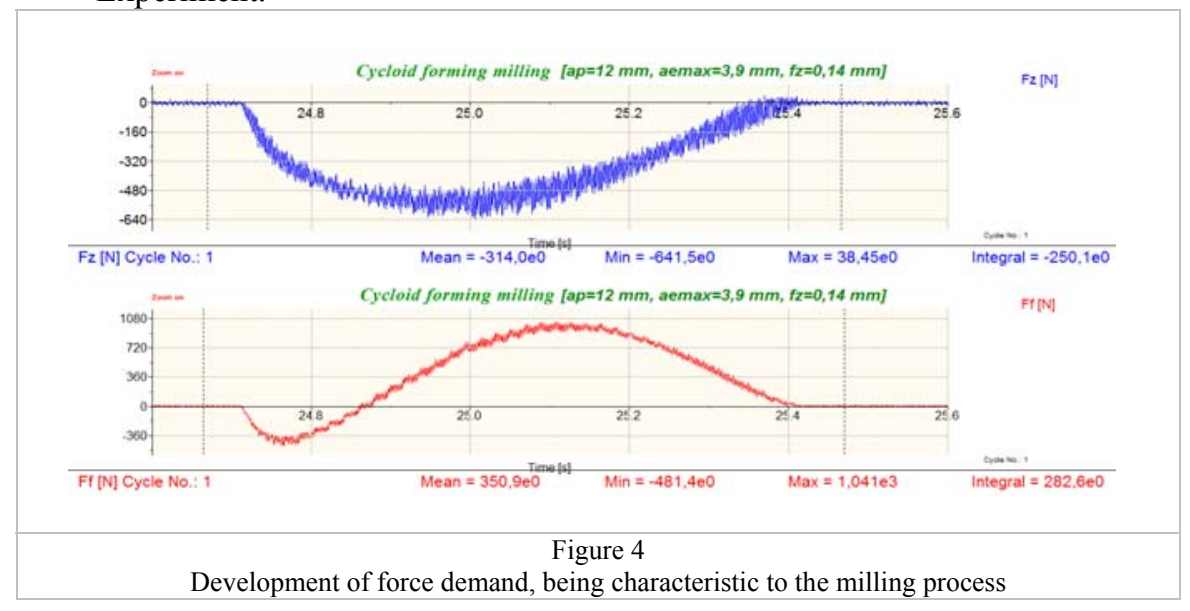

- Analysing the feed force samples (the lower part of Figure 4) it can be noticed that the tool firstly is trying to pull (-), after that trying to push $(+)$ the workpiece. Considering the fact that the negative values play a dominant role in the force development therefore they have a significant distortion effect when calculating the average values (,Mean”). Processing the results of the trials, executed based on DoE, the values of six settings are not able to describe the effect of cutting parameters, performed on the feed force components, with enough certainty therefore it may be necessary to carry out the test for the seventh setting, planned originally as a check test.

The force effect results, measured in case of the planned settings, are processed with a three-factor regression program (HAFARE), and the adequacy of the proposed power function model was verified, with the help of two check tests.

It is known that the productivity can be raised by increasing the feed rate per tooth $\left(f_{z}\right)$ in case of constant cutting speed $\left(v_{c}\right)$ and allowance values $\left(a_{p} \times a_{e m}\right)$. Therefore it is necessary to set values of the second block (with increased productivity) beside the first one (with lower efficiency). Having executed the trials in ,accidental" sequence we had the results of $2 \times 6=12$ settings. The program flow is not presented due to space limitations. The describing functions of the average force (Eq. (1) and (2)) components are shown in Figure 5. 


\begin{tabular}{|c|c|c|}
\hline 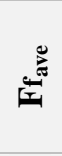 & $\begin{array}{c}\bar{F}_{f}=15.86 \cdot a_{p}^{0.84} \cdot a_{e}^{1.28} \cdot f_{z}^{0.56}[N] \\
\text { Dispersion }= \pm 11 \mathrm{~N} ; \text { Determining index }\left(\mathrm{R}^{2}\right)=0.979 \\
\text { Correlation }=0.9894\end{array}$ & (1) \\
\hline 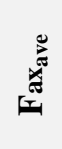 & $\begin{array}{c}\bar{F}_{a x}=-9.28 \cdot a_{p}^{1.13} \cdot a_{e}^{1.5} \cdot f_{z}^{0.88}[N] \\
\text { Dispersion }= \pm 7 \mathrm{~N} ; \text { Determining index }\left(\mathrm{R}^{2}\right)=0.994 \\
\text { Correlation }=0.9973\end{array}$ & (2) \\
\hline & $\begin{array}{c}\text { Figure } 5 \\
\text { Established models of average values of } \mathrm{F}_{\mathrm{f}} \text { and } \mathrm{F}_{\mathrm{ax}}\end{array}$ & \\
\hline
\end{tabular}

The settings Nr. 7E and 8E (i.e. the check tests see in Table 1) confirmed a quite good correspondence and the adequacy of the chosen mathematical model, especially in case of axial force effects. Illustrating the modelled and measured (marked with star) values of the average force components in function of the feed per tooth (Figure 6), it can be seen that the measured values show a very good correlation with the calculated values of Figure 5. Analysing the diagram it can be stated that the double increase of the milling process productivity (from $\mathrm{f}_{\mathrm{z}}=0.08$ to $f_{z}=0.16 \mathrm{~mm}$ ) increased the average values of feed force only by 30 percent, while the growth is $40-50$ percent in case of axial force. Based on the steady chip detachment, observed during the milling tests, and on the decreasing tendency of the noises, we can declare that the increase of the feed value - despite of the increasing force components - had a positive effect on the dynamic process and on the phenomena in connection with the vibrations.

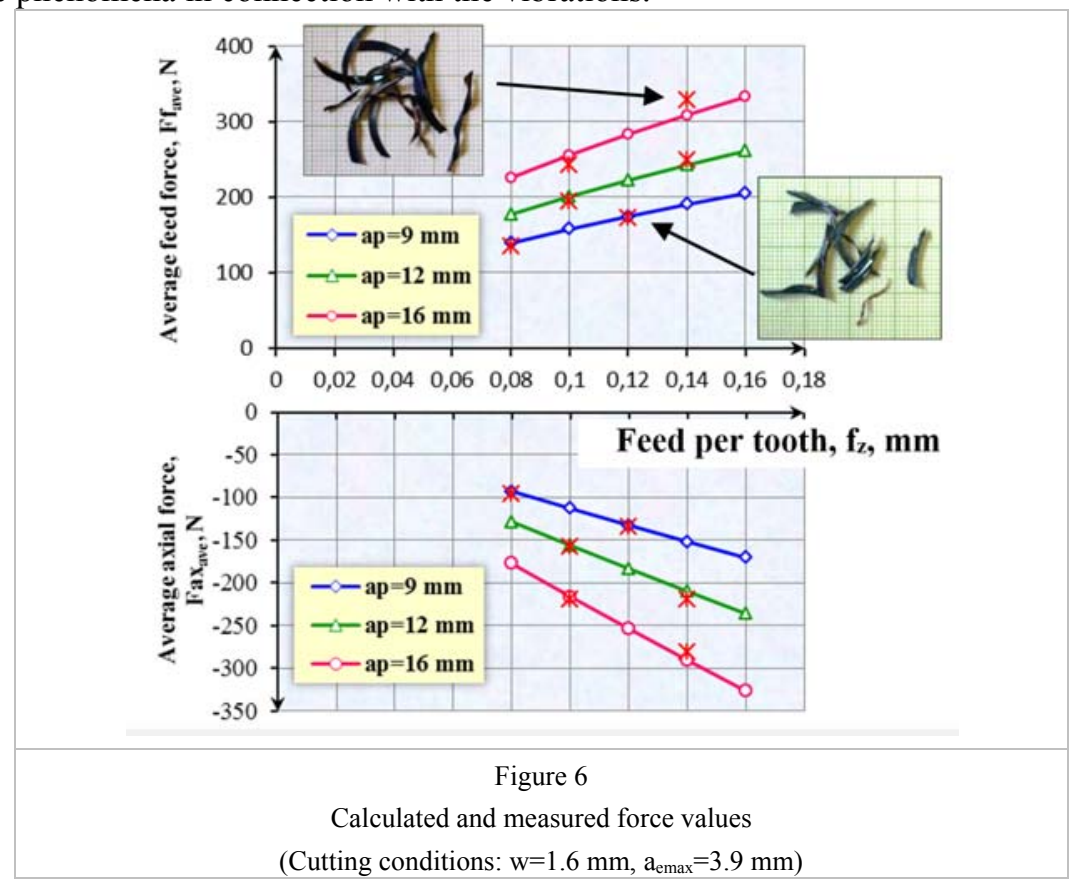


During the general milling tests, executed parallel with these tests (cutting conditions are: $\mathrm{a}_{\mathrm{p}}=16 \mathrm{~mm}, \mathrm{f}_{\mathrm{z}}=0.1 \mathrm{~mm}$ ), even fivefold greater average feed and axial force values were measured; furthermore, much more intense vibrations and ear-splitting noises were observed. If only the discolouration and deformation of the detached chips were compared, then the conclusion that the heat deformation of the trochoidal milling process is more favourable, compared to the traditional (general) groove machining, could be drawn.

The approach to the limit load occurred in case of the sixth setting (see Table 1).

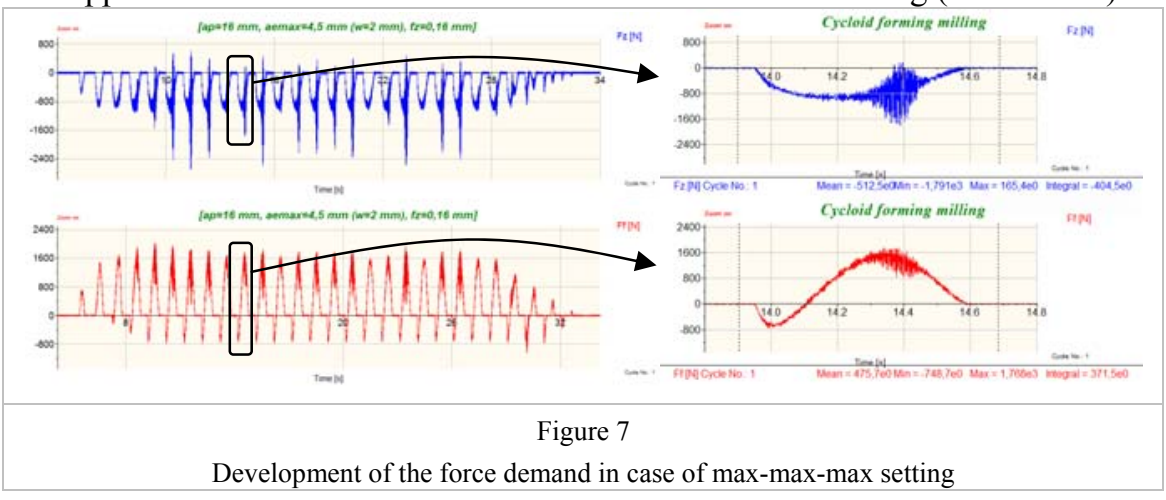

In case of setting the maximal values (Get the maximum from everything!) intense vibrations developed during the tests. It is confirmed not only by the registered force development curve (Figure 7), but by the vibration marks on the side walls and on the bottom of the machined groove as well. Keeping the further usability of the tool in mind, it is recommended not to apply these cutting parameters.

\subsection{The Productivity and Accuracy of the Cycloid-Forming Trochoidal Milling (CTM)}

The material removal rate $\left(\mathrm{MRR}, \mathrm{V}^{\prime} \mathrm{cm}^{3} / \mathrm{min}\right.$ ) is used mainly to characterise the productivity: it establishes a clear order among the different types of trochoidal and similar milling [4]. From the aspect of the productivity it is determinant in case of CTM movement cycle that approx. 50 percent of the tool path can be considered as dead time (it means the tool does not work at this time), therefore it is very strongly recommended to minimise down time. Maybe a good solution is to use the so-called parametrical programming, dispersing more and more: in this case the dead-time lengths can be covered by the tool, applying an increased feed.

The function connection of the material removal rate can be determined by the formula (3) with a low dispersion $\left( \pm 0.17 \mathrm{~cm}^{3} / \mathrm{min}\right)$ and a very good correlation (0.9995):

$V^{\prime}=1.11 \cdot a_{p}^{0.98} \cdot a_{e}^{1.53} \cdot f^{1.03}\left[\mathrm{~cm}^{3} / \mathrm{min}\right]$ 
Analysing the curve of function it can be seen that there is a (nearly) linear connection between the axial depths of cut and feed per tooth from the cutting parameters, while the greatest effect is performed by the length of radial contact. It is logical as the radial step over $(\mathrm{w})$ is the base when programming the trochoidal tool path, the radial depth of cut $\left(\mathrm{a}_{\mathrm{e}}\right)$ is just a consequence of the step over. The step over has a tight correlation with the tool diameter and groove width, from all of these parameters the maximal value of the radial depth of cut $\left(\mathrm{a}_{\mathrm{emax}}\right)$ can be determined.

Table 2

The maximal values of the radial depth of cut $\left(\mathrm{a}_{\mathrm{emax}}\right)$

\begin{tabular}{|c|c|c|c|c|}
\hline \multicolumn{3}{|c|}{$\begin{array}{c}\text { The radial step overs and the calculated maximal } \\
\text { values of radial depth of cut }\end{array}$} & $\mathrm{ae}_{\max }$ & $\mathrm{w}$ \\
\hline $\begin{array}{c}\mathrm{w}=1.2 \\
\left(\mathrm{a}_{\mathrm{emax}} \approx 3.2\right)\end{array}$ & $\begin{array}{c}\mathrm{w}=1.6 \\
\left(\mathrm{a}_{\mathrm{emax}} \approx 3.9\right)\end{array}$ & $\begin{array}{c}\mathrm{w}=2 \\
\left(\mathrm{a}_{\mathrm{emax}} \approx 4.5\right)\end{array}$ & & \\
\hline \multicolumn{3}{|c|}{$\begin{array}{l}\text { The maximal values of the radial tool load, } \\
\text { expressed in percent }\end{array}$} & & \\
\hline $27 \%$ & $33 \%$ & $38 \%$ & & \\
\hline
\end{tabular}

Table 2 shows the maximal values of radial tool load in function of the applied step overs, i.e. it is shown how great is the percentage of the tool diameter, being in contact with the workpiece in the moment when the tool has the greatest contact with the material.

During the tests not only the productivity, but the accuracy variantions of the machined grooves were measured as well. The following statement is valid for all trochoidal milling versions: the tool path is curved (it is well demonstrated in Figure 2), as its result, on the side wall of the groove „laces” develop and it may lead to dimensional fault. As its consequence, these milling methods may be used only as roughing machining. The dimensional fault always means a size, being smaller than the groove width; it depends mainly on the step over and on the tool diameter. In order to study the degree of the differences, the accuracy of the machined grooves, prepared according to the settings of design of experiment, was measured by a calibrated sliding caliper with a resolution of $0.01 \mathrm{~mm}$, produced by Mitutoyo and equipped with a dial gauge. Figure 8, drawn based on the gained results, shows the deviation from the nominal groove width of $16 \mathrm{~mm}$ in function of the radial step over. (The calculated maximal values of radial contact are indicated in round brackets, next to the values of step over.) 


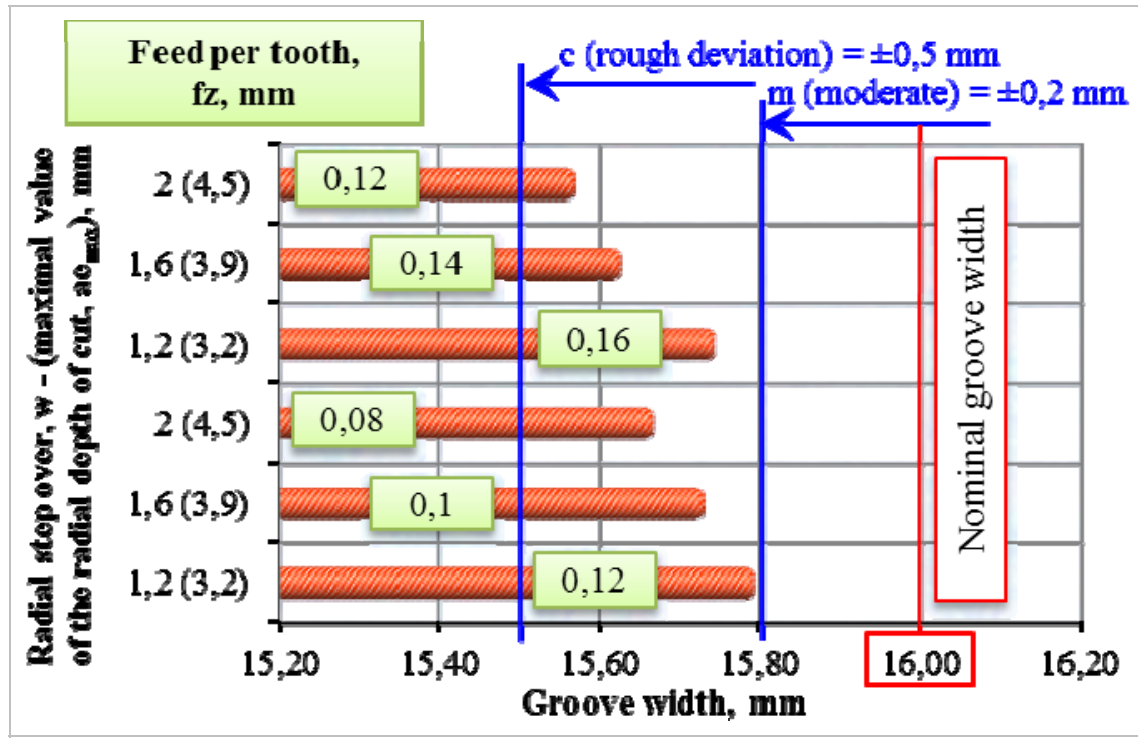

Figure 8

The width values of the machined grooves $\left(a_{p}=12 \mathrm{~mm}\right)$

The measured values, shown in Figure 8, can be classified into tolerance classes; they belong to the class ,c" (rough deviation) and „m” (moderate). Analysing the diagram, it can be stated that during the trials grooves, having „c" tolerance class, were produced. From the tendency it became clear that by optimising data settings an accuracy of $\pm 0.2 \mathrm{~mm}$ may be achieved, belonging to tolerance class „,m”.

Processing the inaccuracies of the machined grooves (it is the double value of the degree of the lace development) by a three-factor regression model, a very low dispersion $( \pm 0.02 \mathrm{~mm})$ and an outstanding good correlation (0.98) were received. The mathematical model is the following:

$\Delta b_{w}=0.3 \cdot a_{p}^{0.31} \cdot w^{1.3} \cdot f_{z}^{0.65} \quad[\mathrm{~mm}]$

It means that the fault degree is influenced by the radial step over to the greatest extent, while the feed rate per tooth and the axial contact have only a degressive effect. Based on the model a clear picture may be drawn which from the applied cutting data and to what degree is „responsible" for the calculated and measured inaccuracy. Starting from this information and applying the equation (4), describing inaccuracy, the grooves may be milled also with CTM technology within the prescribed fault limitation [6]. A report on the data generation, executed with multipurpose optimisation, and its practical tests will be presented in our next paper.

Based on the experiences, gained from the tests, there is an absolutely different situation in case of general milling. This finishing technology, used to produce 
more accurate grooves, generates groove width that is greater than prescribed. For example, by applying machining parameters of $\mathrm{d}=\mathrm{a}_{\mathrm{p}}=12 \mathrm{~mm}$ and $\mathrm{f}_{\mathrm{z}}=0.1 \mathrm{~mm}$, grooves were made - one after another - with a width of $16.3 \mathrm{~mm}$. It can be clearly explained by the fact that even a solid carbide tool runs ,tottering” due to the high radial load.

\subsection{The Microgeometrical Analysis of the Cycloid-Forming Trochoidal Milling (CTM)}

In the previous chapters of the present paper the reason of lace formation and the effect, performed by the adjusted data, were introduced. The high-resolution presentation of waviness and roughness of the laces and their characterisation will follow in this section. During the measurements, executed on a Perthen-Mahr large-scale device, with tracing length (Lt) of $17.5 \mathrm{~mm}$, measuring cut-off wavelength (cut-off, Lc) is $2.5 \mathrm{~mm}$ and measuring length $(\mathrm{Lm})$ is $12.5 \mathrm{~mm}$. The research included the analysis of the filtered (so-called R-system) and unfiltered, full profiles as well (P-system).

On the enlarged images of Figure 9, the deviations are shown well. The surface profile was registered - due to the degree and size of the lace formation - in a length of $\pm 50 \mu \mathrm{m}$ on the side wall and in a length of $\pm 30 \mu \mathrm{m}$ on the bottom of the groove (the R-system is shown on the upper part, the P-system with full profile on the lower part of figure).

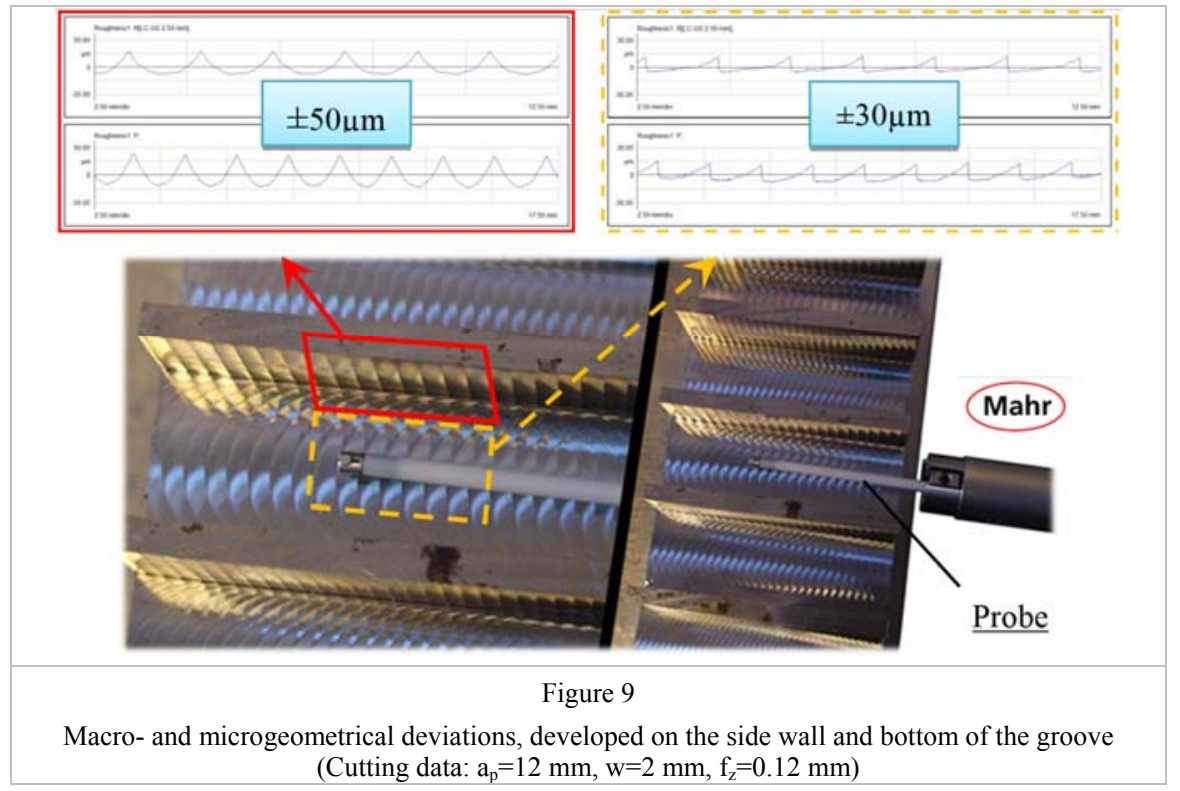


Considering the fact that the roughness, formed on the side wall of groove, cannot be classified as microgeometrical deviations, therefore its modelling as roughness may lead to a wrong result. The lace development on the side wall is considered as a first-class deviation, i.e. as a form error, and according to DIN 4760 it is to be classified as macrogeometrical deviations. This form error - resulting from the characteristics of this machining process - may cause even a size error and it has a tight connection with the groove accuracy, mentioned in the previous chapter.

The analysis of the roughness values, measured on the bottom of the machined grooves (in the further part of the present article we are going to deal only with them), was set back only by one circumstance, it was the limit load (the 6th setting in the first block), already mentioned in the present paper. Its negative effect on the process could have been measured even in case of the surface roughness on the bottom of the groove. The average $(-410 \mathrm{~N})$ and the maximal values $(-2100 \mathrm{~N})$ of the axial tool load were so significant that they caused vibrations and the marks of the tool edges were simple „copied” on the surface. Compared to the registered roughness parameters, resulting from other settings, three-five times worse roughness values were measured in this case.

Excluding the limiting load values, the connection between the cutting parameters and the measured unevenness height $(\mathrm{Rz})$ was analysed. The surface of the machined grooves was described with a low dispersion and with an unusual high correlation with the help of the following models:

Roughness model of profile, measured in R-system

$$
R_{z}=7.6 \cdot a_{p}^{0.64} \cdot w^{1.04} \cdot f_{z}^{0.68} \quad[\mu m]
$$

Dispersion $= \pm 0.4 \mu \mathrm{m}$; Determining index $\mathrm{R}^{2}=0.988$;

$$
\text { Correlation }=0.994
$$

Roughness model of profile, measured in the full profile P-system

$$
\begin{gathered}
R_{z}(\mathrm{JIS} 1982)=10.33 \cdot a_{p}^{0.59} \cdot w^{0.95} \cdot f_{z}^{0.66}[\mu \mathrm{m}] \\
\text { Dispersion }= \pm 0.3 \mu \mathrm{m} ; \text { Determining index } \mathrm{R}^{2}=0.995 \\
\text { Correlation }=0.9977
\end{gathered}
$$

Both models (Eq. (5) and (6)) certify that the roughness, formed on the bottom of the groove, is linearly influenced by the step over and the feed rate per tooth but the axial contact has a degressive character (with the exception of the limit load).

The Figure 10 shows the Rz roughness characteristics, evaluated by both surface profile measuring systems. The calculated and measured (marked with $\mathrm{x}$ ) values show that by increasing the feed parameters, the roughness values degrade, showing a slightly degressive character. The best roughness can be achieved in case of machining grooves with a depth of $9 \mathrm{~mm}$, while the worst is in case of grooves with $16 \mathrm{~mm}$ depth. This statement confirms the fact that the max-maxmax setting is to be avoided from the aspect of the roughness as well. 


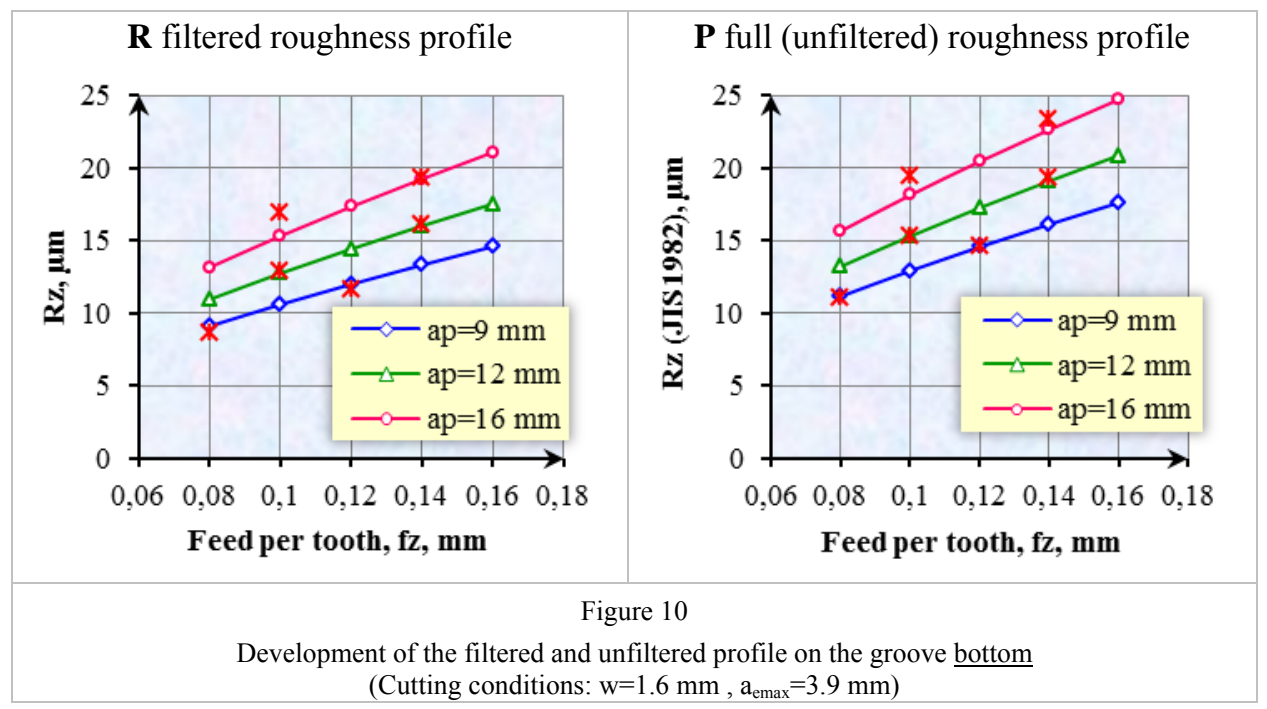

In connection with Figure 10 it must be emphasised that the $\mathrm{Rz}$ values of unfiltered profiles are by $2-5 \mu \mathrm{m}$ greater, compared to the numbers, resulting from the filtered profile. Further research results, concerning this topic will be published in the next releases within the frame of TÁMOP-project.

\section{Conclusions, further tasks}

The main goals of the test series, executed based on Design of Experiment, were realised. The connection between the applied data $\left(a_{p}, w, a_{e}, f_{z}\right)$ and certain technical-economical features (force demand, productivity, accuracy, roughness) has been modelled with the help of power functions as it is used in the technological practice. By applying the proposed mathematical models, it can be described which parameters and to what degree influence the process characteristics. Having processed the results of two blocks, based on the applied DoE, not only functions with low dispersion and high correlation were received, but they were able to determine the limiting values of CTM, when the productivity is increased.

As further task it is definitely reasonable to carry out researches, determining the data settings of the most productive cycloid-forming milling, taking the prescribed accuracy into consideration. The programming and preliminary examinations of other trochoidal milling methods have already been executed, in this way we have the possibility to carry out detailed, or even long-lasting tests of any of these research tests in the future. A good possibility would be to test extreme material grades (for example, heat-resistant super-alloys) as well. 


\section{Acknowledgements}

The project was realised through the assistance of the European Union, with the co-financing of the European Social Fund, namely: TÁMOP-4.2.1.B-11/2/KMR 2011 - 0001: Researches on Critical Infrastructure Protection.

\section{References}

[1] Bakondi, K. - Kardos, Á.: A gépgyártás technológiája III. Tankönyvkiadó, Budapest, 1974

[2] Präzisionswerkzeuge Klaus-D. Dung GmbH \& Co KG: High - Performance - Cutting, HPC Fräser, Ausgabe HPC-010-1, Wolfsburg (Germany), 2012

[3] Szalóki I.: Trochoidális pályák programozása Microsoft Office Excel alkalmazásban, ÓE / BGK / Forgácsolástechnológia számítógépes tervezése feladat, Budapest, 2012. p. 30

[4] Szalóki, I. - Csesznok, S. - Csuka, S - Sipos, S.: Can trochoidal milling be ideal? Manufacturing 2012 The XXI. Conference of GTE on

Manufacturing and related technologies, Budapest, November 15-16. 2012.

Session \#5, CD version, S6_08., pp. 10. ISBN 978-963-9058-35-4

[5] Seco Tools AB: Trochoidal Milling Excel application, Fagersta (Sweden), 2005

[6] Mózes, A. - Tállai, P. - dr. Sipos, S.: Új fejlesztésű száras marószerszámok alkalmazási sajátosságai, Óbuda University, e-Bulletin Vol. 2, No. 1, 2011, pp. 385-390 